IN THE late 1960 s travellers' tales suggested that Russians were having some success in detecting premonitory symptoms to eanthquakes. Physical properties of rocks in Central Asia were said to change prior to quakes, although Western geophysicists, deeply immersed in plate tectonics and lacking any sight of the Russian data, were not moved to do much. Then in 1972 American interest suddenly grew explosively. By early 1973 precursors to earthquakes had been seen in many parts of the world, a dilatancy theory had been proposed to explain the observations and a simple relationship between the duration of the precursor and the size of the earthquake had been suggested. The annual American Geophysical Union meeting in April 1973 was a heady experience. This year's meeting was sober by comparison, and there was much concern about funding.

The situation is a classical one of what one could call the four black spots of present day science policy:

Too many people chasing too little money.

- Government, industry and universities working in the same field.

- The political need for a missionoriented approach in conflict with scientists' desire for in-depth understanding.

- The problem that the contractural system poses for the university scientist.

On the scientific side, it had been a relatively quiet year. There had been two instances, one in New York State, the other in Riverside, California, where events had been foretold by means of variations in seismic wave travel times before the earthquake. The same technique was also showing some promise in other places, although there seemed a growing feeling that the quality of data was often inadequate and that the near-focal conditions are vastly more complex than a first modelling would suggest. On the other hand there is promise both in gravimetric and tilt observations and some of the laboratory and field experiments (including earthquake control by fluid injection) have gone well.

Responsibility for the American 'earthquake hazard reduction programme' is vested in the US Geological Survey (USGS). Much more than prediction is covered-risk analysis, mapping and rock mechanics are other fields of activity. In the fiscal year July 1971-June 1972 (FY 1972) the programme amounted to $\$ 1.6$ million, but the impact of the San Fernando earthquake put up the allocation to $\$ 4$ million by FY73. In moving into FY74, the first year in which prediction could be discussed seriously, the USGS found itself picking up responsibility for earthquake work previously done by the National Oceanographic and Atmos-

\section{Quake prediction no bonanza}

\section{David Davies}

pheric Administration (NOAA) and fluid injection studies of the Advanced Research Projects Agency (ARPA). Thus although the budget for FY74 was $\$ 8.6$ million, by no means all the increase was in the form of new money for research. The figure shows the distribution. Apart from sole-source contracts-for instance to support seismic networks operating at present, universities, state governments and industry had $\$ 1.3$ million to fight over. No increase is seen in this sum for FY75. "We need a big earthquake to shake more money out of the government" as one official put it.

The figure of $\$ 1.3$ million took many by surprise, as it was generally expected that in the mid-1970s the USGS would dispense the largesse that in the past had come from ONR, NASA, NSF and ARPA and which had made for so many thriving geophysical laboratories. External funding applications for FY74 amounted to $\$ 13$ million from two

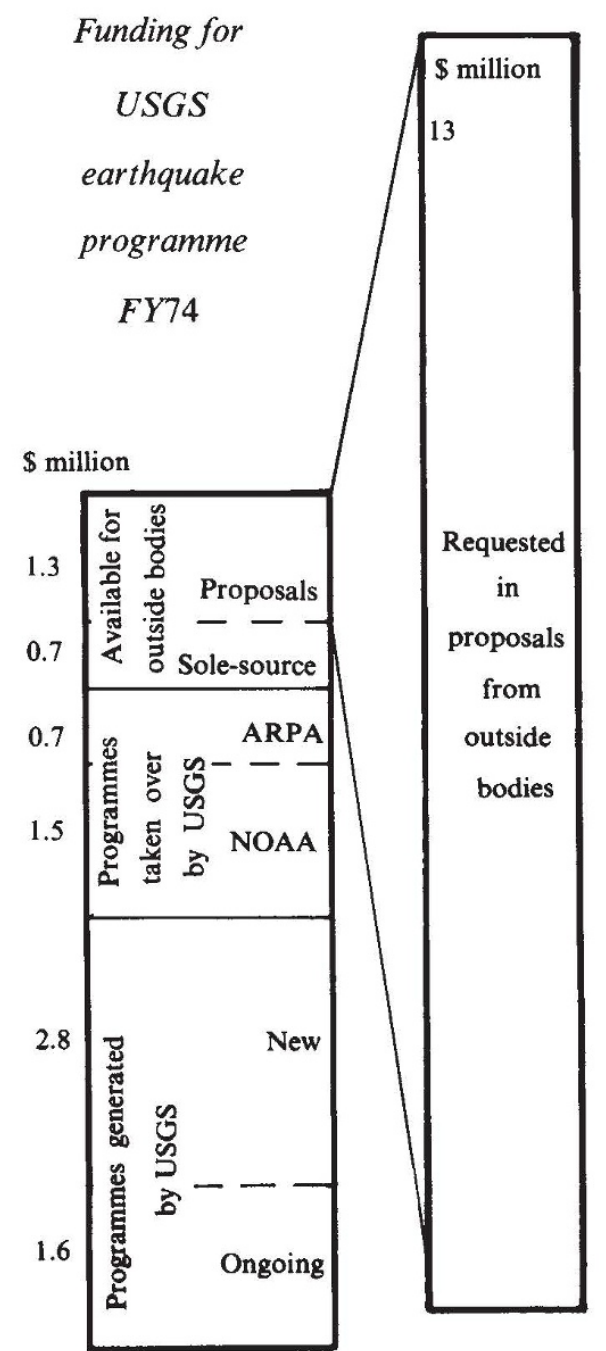

hundred proposals - the USGS is able to support 32 of them. On one official's reckoning it could have intelligently used $\$ 8$ million this fiscal year. Expertise is going unused, he thinks. As it is, some seismic stations in California have already closed for lack of funding. Other agencies no longer have a charter to do research in this field, so failure with the USGS really does mean failure to fund. The prediction programme is a very lean operation in which immediate relevance is necessary of every project. "A hard-nosed missionoriented approach" as one project officer described it-himself with a modest fame as having already engendered such an approach in three other government agencies.

It is inevitable that there is conflict in such an underfunded situation. More generalised and global research suffers at the hands of the more particular and American. There is a suspicion that the USGS will swallow up all the good ideas that come from outside (university scientists pointedly remark that the first good papers in the subject came from MIT, Stanford, Columbia and Caltech, not the big government laboratories which now have most of the available money). And, most immediate, people in universities suddenly find themselves up against government contracts officers, zealous to ensure scrupulous accounting. It is this more than anything else which seems to have persuaded rational men that they are being persecuted. The staff of the USGS are aware of these undercurrents of bitterness and are trying to establish better headquarters procedures.

There are some very obvious defects at the moment and action needs to be taken at governmental level (university scientists are also going to have to learn to live with the system a bit more). The lack of funds is quite ludicrous. The United States loses on average $\$ 630$ million annually through earthquake damage-a figure which will doubtless go up when California next suffers a serious quake. To keep talent out through lack of one-hundredith of that sum is a false economy. Worse, it is worrying that the programme is required to be so nationally oriented (the USGS is, of course, part of the Department of the Interior). Most countries look to their own scientists to solve their own problems, but the Western world has increasingly looked to the United States to grapple with global problems, at risk of being branded imperialists. If ever there were a problem knowing no frontiers this is it, and success would be that much more likely if more American geophysicists could be financially encouraged to think and collect data in a more global framework. 